\title{
APLICAÇÃO SEQÜENCIAL DE HERBICIDAS DE MANEJO NA IMPLANTAÇÃO DA CULTURA DO FEIJOEIRO-COMUM EM SISTEMA DE PLANTIO DIRETO
}

\author{
Luiz Alberto Kozlowski ${ }^{1}$
}

\footnotetext{
${ }^{1}$ Eng. ${ }^{\circ} \mathrm{Agr}^{\circ}$., MSc., Professor Adjunto. Faculdade de Agronomia, Pontifícia Universidade Católica do Paraná. Caixa Postal 16210. Curitiba, PR 81611-970 kozlowsk@),rla01.pucpr.br
}

\begin{abstract}
RESUMO
A aplicação seqüencial de herbicidas antes da semeadura pode ser usada como estratégia para reduzir o efeito da competição das plantas daninhas com o feijoeiro devido a eliminação do primeiro fluxo de emergência das plantas daninhas. O objetivo do trabalho foi avaliar as vantagens da aplicação seqüencial de herbicidas de manejo em plantio direto de feijão, com a eliminação do primeiro fluxo de emergência das plantas daninhas antes da semeadura e o efeito deste sistema de manejo na eficácia dos herbicidas pós-emergentes. O delineamento experimental utilizado foi o de blocos ao acaso, com quatro repetições e os tratamentos testados nas parcelas foram: sulfosate ( $396 \mathrm{~g} / \mathrm{ha}$ e.a.), aos 20 dias antes da semeadura com um tratamento suplementar de paraquat (200 g/ha); paraquat + diuron (200 + $100 \mathrm{~g} / \mathrm{ha})$; diquat (200 g/ha); paraquat/diuron + diquat (100/50 + $100 \mathrm{~g} / \mathrm{ha})$, na semeadura (aplicação seqüencial de manejo - ASM); sulfosate + 2,4 D (594 + 720 g/ha) aos 10 dias antes da semeadura (aplicação única de manejo - AUM) e uma testemunha sem controle. As aplicações nas subparcelas foram: fomesafen + fluazifop-p-butil $(100+80 \mathrm{~g} / \mathrm{ha})$, fomesafen/fluazifop-p-butil + bentazon $(100 / 80+420 \mathrm{~g} / \mathrm{ha}) \mathrm{e}$ uma testemunha sem tratamento. Aos 7 dias depois da semeadura não houve diferenças significativas entre ASM e AUM, ambos com controle das plantas daninhas acima de $85 \%$. Não houve diferenças significativas entre os pós-emergentes, ambos com eficácia no controle das plantas daninhas acima de $98 \%$, independente do sistema de aplicação de manejo. Na semeadu$\mathrm{ra}$, as parcelas com AUM apresentavam densidade das plantas daninhas menor (71\%) do que nas parcelas com ASM. No momento da aplicação dos pós-emergentes, a densidade das plantas daninhas foi menor (41\%) em ASM em relação a AUM, com um estádio de desenvolvimento mais favorável das plantas daninhas para o controle em pós-emergência.
\end{abstract}

Palavras-chave: fomesafen / fluazifop-p-butil, sulfosate, bentazon, paraquat, diuron, diquat, manejo, plantio direto.

\section{ABSTRACT \\ Sequential application of burndown herbicides in the establishment of no-tillage systems in common bean}

The sequential application of herbicides at pre-planting can be used as a strategy to reduce the effect of weed competition with bean plants through the elimination of the first flushes of emergence of weeds. The objective of this research was to evaluate the advantages of sequential application of burndown herbicides in beans grown under no-tillage, with the elimination of first emergance flushes of weeds prior to planting, and their impacts on the effectiveness of post-emergence herbicides. The experimental design used was randomized blocks with four replications and the treatments in the main plots consisted of 
burndown herbicides: sulfosate ( $396 \mathrm{~g} / \mathrm{ha}$ a.e.) at 20 days before planting with a supplementary treatment of paraquat ( $200 \mathrm{~g} / \mathrm{ha})$, paraquat + diuron $(200+100 \mathrm{~g} / \mathrm{ha})$, diquat $(200 \mathrm{~g} / \mathrm{ha})$, paraquat/diuron + diquat $(100 / 50+100 \mathrm{~g} / \mathrm{ha})$ at planting (sequential application of burndown - SAB); application of sulfosate $+2,4 \mathrm{D}(594+720 \mathrm{~g} / \mathrm{ha}$ a.e.) 10 days before planting (only one burndown application - OBA) and an untreated control. The sub-plots consisted of post-emergence herbicides: fomesafen + fluazifop-p-butyl $\left(100+80 \mathrm{~g}\right.$ a.i. ha $\left.{ }^{-1}\right)$, (fomesafen + fluazifop-p-butyl) + bentazon $\left((100+80)+420 \mathrm{~g}\right.$ a.i. ha $\left.{ }^{-1}\right)$ and an untreated control was also included. At 7 days after planting there was no difference between the SAB and OBA, both which controlled up to $85 \%$ of the weeds. There was no difference between the two post-emergence herbicides, both with effectiveness in the control of weeds up to $98 \%$, independent of application of burndown herbicides. At the time of planting, the plots with OBA had lower weed density (71\%) than the plots treated with SAB. In addition, at the time of postemergence herbicide application, the density of weeds was lower (41\%) with the SAB than the OBA plots, with a more favorable stage of development of weeds for the post-emergence control.

Keywords: fomesafen, fluazifop-p-butyl, sulfosate, bentazon, paraquat, diuron, diquat, burndown, no-till.

\section{INTRODUÇÃO}

A principal característica do sistema plantio direto é o não revolvimento do solo; em conseqüência, os resíduos das culturas anteriores, adubação verde e infestantes ficam sobre o terreno, formando o que se designa de cobertura morta. Nesse sistema depende-se inteiramente do uso de herbicidas antes da semeadura das culturas, para a eliminação das plantas daninhas já estabelecidas, com a operação de manejo ou dessecação, sendo um fator importante para o sucesso deste sistema, pois substituem o arado e a grade no preparo do solo. Na operação de manejo ou dessecação são utilizados exclusivamente herbicidas não seletivos e de ação total (Almeida, 1991; Velloso \& Souza, 1993; Buzatti, 1999).

Em muitos casos, na operação de manejo são utilizadas misturas de herbicidas, como os ingredientes ativos glyphosate, paraquat e 2,4-D, porém para estas misturas, devese observar um período, em torno de dez dias, para realizar a semeadura, devido aos resíduos de 2,4-D no solo que podem causar fitotoxicidade à cultura, além de que, algumas vezes verificam-se respostas antagônicas no controle das plantas daninhas com estas misturas (O'Donovan \& O'Sullivan, 1982a, 1982b).

Para se evitar problemas com a retenção de resíduos de herbicidas na superfície do solo, em restos culturais (Bauman \& Ross, 1983) ou então possíveis efeitos alelopáticos dos restos vegetais sobre a cultura, o manejo químico da cobertura vegetal deve ser antecipado e realizado no mínimo 20 dias antes da semeadura da cultura (Roman \& Velloso, 1993).

A cobertura vegetal morta ou viva influencia a incidência da radiação solar que atinge a superfície do solo, provocando mudanças na temperatura e no conteúdo de umidade do solo ao longo do tempo, sendo que estes fatores tem influência direta nos fluxos de emergência de plântulas no campo (Carmona, 1992).

A aplicação seqüencial de herbicidas de manejo proporciona uma oportunidade para eliminar vários fluxos de emergência de plantas daninhas que ocorrem antes da seme- adura da cultura, reduzindo a densidade das plantas daninhas durante a emergência e crescimento inicial da cultura, aumentando assim o seu crescimento, competitividade e produção (Vidal et al., 1999).

O objetivo do trabalho foi avaliar as vantagens da aplicação seqüencial de herbicidas no manejo de áreas para plantio direto do feijoeiro, com a eliminação do primeiro fluxo de germinação das plantas daninhas imediatamente após a semeadura e avaliar o efeito da utilização deste sistema de manejo sobre o uso e eficácia dos herbicidas de pós-emergência.

\section{MATERIAL E MÉTODOS}

O trabalho experimental de campo foi conduzido durante a safra 1999/2000, na Fazenda Experimental Gralha Azul, da Pontifícia Universidade Católica do Paraná, município de Fazenda Rio Grande, PR. A região apresenta clima do tipo Cfb (IAPAR, 1976) e solo pertencente à unidade de mapeamento associação Latossolo Vermelho-Amarelo Álico + Cambissolo Álico, com horizonte A proeminente, textura argilosa, fase sub-tropical, relevo suave ondulado (Olmos et al, 1984).

O delineamento experimental utilizado foi de blocos ao acaso com tratamentos em parcelas subdivididas, com quatro repetições. Os tratamentos testados nas parcelas foram cinco diferentes opções de manejo químico aplicados em duas épocas: aos 20 dias antes da semeadura, aplicação seqüencial de manejo (ASM) e aos 10 dias antes da semeadura ou aplicação única de manejo (AUM), tendo um tratamento testemunha sem manejo químico. Nos tratamentos de manejo, realizados aos 20 dias antes da semeadura, foi feito um segundo manejo químico, dessecação seqüencial, no dia da semeadura, com o objetivo de eliminar novos fluxos de emergência das infestantes. Os tratamentos testados nas subparcelas foram duas opções de herbicidas aplicados em pós-emergência: aplicação com $50 \%$ da dose recomendada e quando as plantas daninhas alvos apresentavam quatro folhas verdadeiras desenvolvidas e uma testemunha sem apli- 
Aplicação seqüencial de herbicidas...

Tabela 1. Herbicidas, doses e épocas de aplicação para o manejo químico nas parcelas. Fazenda Experimental Gralha Azul/ PUC, Fazenda Rio Grande, PR. 1999/2000.

\begin{tabular}{lccccc}
\hline \multicolumn{1}{c}{ Tratamento } & $\begin{array}{c}\text { Dose } \\
\text { (g/ha e.a.) }\end{array}$ & Época & Tratamento seqüencial & $\begin{array}{c}\text { Dose } \\
\text { (g/ha) }\end{array}$ & Época \\
\hline Sulfosate+2,4-D & $594+720$ & $10 \mathrm{DAS}^{1}$ & ---- & ---- & ---- \\
Sulfosate & 396 & $20 \mathrm{DAS}$ & Paraquat & 200 & $\mathrm{NS}^{2}$ \\
Sulfosate & 396 & $20 \mathrm{DAS}$ & Paraquat+diuron & $200+100$ & $\mathrm{NS}$ \\
Sulfosate & 396 & $20 \mathrm{DAS}$ & Diquat & 200 & $\mathrm{NS}$ \\
Sulfosate & 396 & $20 \mathrm{DAS}$ & Paraquat/diuron+diquat & $100 / 50+100$ & $\mathrm{NS}$ \\
Testemunha & ---- & ---- & ---- & --- & --- \\
\hline
\end{tabular}

'Dias antes da semeadura

${ }^{2} \mathrm{Na}$ semeadura

cação. O tamanho da parcela foi de $2 \mathrm{~m}$ de largura (5 fileiras) $\mathrm{x}$ $18 \mathrm{~m}$ de comprimento, com área útil de $1,2 \mathrm{~m}$ (3 fileiras) $\mathrm{x} 16,0 \mathrm{~m}$ comprimento, ao passo que para as subparcelas o tamanho foi de $2 \mathrm{~m}$ de largura ( 5 fileiras) $\mathrm{x} 6 \mathrm{~m}$ de comprimento, com área útil de $1,2 \mathrm{~m}$ ( 3 fileiras) $\times 4 \mathrm{~m}$ de comprimento. Os tratamentos aplicados às parcelas e subparcelas são apresentados nas Tabelas 1 e 2, respectivamente.

$\mathrm{Na}$ área experimental foi instalada a cultura do feijoeiro, com semeadura realizada em 20 de janeiro de 2000 , utilizando-se plantadeira tracionada com trator, que estabeleceu fileiras espaçadas de $0,40 \mathrm{~m}$ entre si. A semeadura foi realizada de acordo com a tecnologia recomendada para a cultura, realizando-se adubação e tratamentos fitossanitários para que os feijoeiros se desenvolvessem normalmente. Foi utilizada a variedade de feijão FT Nobre, grupo comercial preto, hábito de crescimento indeterminado, tipo II, ereto.

Os tratamentos de manejo nas parcelas foram realizados em 31 de dezembro de 1999 e em 10 de janeiro de 2000, para a ASM e AUM, respectivamente. A segunda aplicação de manejo no ASM foi realizada em 20 de janeiro de 2000 , imediatamente após a semeadura do feijoeiro, de acordo com a Tabela 1. Os tratamentos de pós-emergência nas subparcelas foram realizados em 5 de fevereiro de 2000, de acordo com a Tabela 2 .

Os herbicidas foram aplicados usando-se equipamento de precisão, pressurizado com $\mathrm{CO}_{2}$, provido de barra contendo quatro pontas de jato plano em leque, marca Teejet $\mathrm{XR}$ 110.02 VS, espaçados entre si de $0,5 \mathrm{~m}$, com volume de cal-

Tabela 2. Herbicidas e doses para a aplicação em pós-emergência nas subparcelas. Fazenda Experimental Gralha Azul/PUC, Fazenda Rio Grande, PR. 1999/ 2000

\begin{tabular}{lc}
\hline \multicolumn{1}{c}{ Tratamento } & Dose (g/ha) \\
\hline Fluazifop-p-butil+fomesafen & $80+100$ \\
Fluazifop-p-butil/fomesafen+bentazon & $80 / 100+420$ \\
Testemunha sem herbicida & ---- \\
\hline
\end{tabular}

da de $135 \mathrm{l} /$ ha e pressão de aspersão de $1,0 \mathrm{~kg} / \mathrm{cm}^{2}$. Na segunda aplicação seqüencial de manejo (ASM), foi adicionado o surfactante Agral (0,5\% v.v.) aos herbicidas, de acordo com as recomendações do fabricante. As condições ambientais no momento da aplicação dos tratamentos de manejo foi de céu sem nuvens, temperatura do ar de $27^{\circ} \mathrm{C}$, umidade relativa do ar de $68 \%$ e velocidade do vento de 5 a $6 \mathrm{~km} / \mathrm{h}$. Para os tratamentos em pós-emergência o céu apresentava-se sem nuvens, com temperatura do ar de $25^{\circ} \mathrm{C}$, umidade relativa do ar de $70 \%$ e vento entre 0 e $5 \mathrm{~km} / \mathrm{h}$.

No dia da semeadura, antes da segunda aplicação seqüencial de manejo (ASM) nas parcelas, foi feita a avaliação visual da percentagem de controle das plantas daninhas, utilizando-se escala visual de $0-100 \%$, onde $0 \%$ representa nenhum controle e $100 \%$ o controle total. Foi feita também a contagem e identificação das espécies de plantas daninhas alvos presentes, em uma área de $0,25 \mathrm{~m}^{2}$, no centro da área útil da parcela, separando por estádio de desenvolvimento.

Nas parcelas que receberam a segunda aplicação seqüencial de manejo (ASM), foi feita, 7 dias após a aplicação, a avaliação visual da percentagem de controle dos tratamentos seqüenciais de manejo, utilizando-se escala visual de $0-100 \%$. As plantas daninhas alvos, objeto de estudo do experimento foram : leiteiro (Euphorbia heterophylla), nabiça (Raphanus raphanistrum) e capim-colchão (Digitaria horizontalis).

No dia e antes da aplicação dos herbicidas de pósemergência nas subparcelas, foi feita a contagem e identificação das espécies de plantas daninhas alvos presentes, em uma área de 0,25 $\mathrm{m}^{2}$, no centro da área útil da subparcela, separando por estádio de desenvolvimento. Após a aplicação dos pós-emergentes, foi feita a avaliação visual da porcentagem de controle aos 7, 14 e 21 dias após o tratamento (DAT), utilizando-se escala visual de $0-100 \%$, onde $0 \%$ representa nenhum controle e $100 \%$ o controle total.

Os dados obtidos foram submetidos à análise de variância e as médias dos tratamentos comparadas entre si pelo teste de Tukey a $5 \%$ de probabilidade. Para a análise de 
variância, os dados de percentagem de controle das plantas daninhas, em relação à testemunha, foram transformados em para homogeneização das variâncias.

\section{RESULTADOS E DISCUSSÃO}

Na Tabela 3, são apresentados os resultados médios, relativos ao nível de controle do manejo da cobertura vegetal, nas avaliações realizadas no momento da semeadura e 7 dias após a semeadura (DAS). Verifica-se que entre as ASM não houve diferenças significativas entre os tratamentos, porém foram superiores a AUM (sulfosate + 2,4-D), no momento da semeadura. Aos 7 DAS, não houve diferenças significativas entre os manejos, ASM e AUM, ambos apresentando bom controle das infestantes. Porém, na ASM, houve a eliminação do primeiro fluxo de emergência das plantas daninhas, fato não observado na AUM, o que proporcionou um menor número de plantas daninhas e maior uniformização do estádio de desenvolvimento das infestantes no momento da aplicação de pós-emergência, refletindo em melhores condições para o crescimento inicial e competitividade da cultura (Souza Neto \& Oliveira, 1999; Vidal et al, 1999, Fleck et al, 2000; Portela \& Cobucci, 2000; Purissimo, 2000).

$\mathrm{Na}$ Tabela 4 são apresentados os resultados médios relativos ao nível de controle geral dos herbicidas de pósemergência sobre as espécies alvos, nas avaliações realizadas aos 7, 14 e 21 dias após o tratamento (DAT). Verifica-se que, independente da época de avaliação, não houve diferenças significativas entre os herbicidas de pós-emergência, quando aplicados sobre as áreas que receberam a AUM ou ASM. Ambos apresentaram eficácia no controle das plantas daninhas alvos acima de $98 \%$ após 14 DAT, ocorrendo diferença significativa apenas para os herbicidas aplicados sobre a testemunha sem manejo químico, uma vez que nessa parcela as plantas daninhas estavam adultas, portanto, fora do estádio de desenvolvimento ideal para o controle com os herbicidas utilizados. Verificou-se que, na avaliação realizada aos 14 DAT, haveria a necessidade de uma nova aplicação de herbicida nas parcelas que receberam a ASM e AUM, devido a um novo fluxo de emergência das plantas daninhas.

Com relação as plantas daninhas alvos, observa-se na Figura 1 (A, C e E), que no momento da semeadura, antes da ASM, a densidade das plantas daninhas na ASM foi de 433,82 e 28 plantas $/ \mathrm{m}^{2}$, ao passo que, para a AUM foi de 41, 23 e 14 plantas $/ \mathrm{m}^{2}$, para leiteiro, nabiça e capim-colchão, respectivamente. Verifica-se que, o nível de infestação das plantas daninhas na AUM, em relação a ASM, foi 90, 72 e 50\% menor para leiteiro, nabiça e capim colchão, respectivamente. Isso mostra que, o manejo antecipado feito na ASM, proporcionou condições para um novo fluxo de emergência das plantas daninhas e com a segunda aplicação seqüencial de manejo estas espécies são eliminadas, de modo a garantir melhores condições para o crescimento inicial e estabelecimento da cultura (Fleck et al., 2000; Portela \& Cobucci, 2000; Purissimo, 2000).

Na Figura 1 (B, D e F) pode-se observar a densidade de plantas daninhas em função do estádio de desenvolvimento no momento da semeadura. Verifica-se que para a AUM, o leiteiro, nabiça e capim-colchão apresentaram um desenvolvimento bastante uniforme, com a totalidade das plantas no estádio de até duas folhas, ao passo que na ASM as mesmas espécies apresentaram um desenvolvimento mais desuniforme, com aproximadamente $86 \%$ do total das plantas no estádio de desenvolvimento de até quatro folhas ou perfilhos, para dicotiledôneas e gramíneas, respectivamente. Isso se deve ao fato de que, com o manejo antecipado em 20 dias antes da semeadura, houve mais de um fluxo de emergência, caracterizado pela presença de plantas com estádio de desenvolvimento variando de duas, duas a quatro ou mais de quatro folhas, fato não observado na AUM. Isso possibilita, após a segunda aplicação seqüencial de manejo, no sistema de ASM, uma maior homogeneização no estádio de desenvolvimento e menor densidade de plantas daninhas quando da aplicação dos herbicidas de pós-emergência.

Tabela 3. Controle (\%) na semeadura e 7 dias após a semeadura (DAS), dos herbicidas aplicados nos manejos (AUM e ASM) para a implantação do feijoeiro. Fazenda Experimental Gralha Azul/PUC, Fazenda Rio Grande, PR. 1999/2000.

\begin{tabular}{|c|c|c|c|}
\hline \multirow{2}{*}{ Tratamento } & \multirow{2}{*}{$\begin{array}{c}\text { Dose } \\
\text { (g/ha) }\end{array}$} & \multicolumn{2}{|c|}{ Controle $(\%)$} \\
\hline & & 7 DAS & Na semeadura \\
\hline Sulfosate $+2,4-D$ & $594+720$ & $70 \mathrm{~b}$ & $89 a$ \\
\hline Sulfosate // paraquat & $396 / / 200$ & 80 a & 86 a \\
\hline Sulfosate // paraquat/diuron & $396 / / 200 / 100$ & $80 \mathrm{a}$ & 89 a \\
\hline Sulfosate // diquat & $396 / / 200$ & $80 \mathrm{a}$ & $89 \mathrm{a}$ \\
\hline Sulfosate // paraquat/diuron + diquat & $396 / / 100 / 50+100$ & $80 \mathrm{a}$ & 88 a \\
\hline Testemunha & $-\cdots$ & $0 \mathrm{c}$ & $0 \mathrm{~b}$ \\
\hline $\mathrm{F}$ & & $4092,8 * *$ & $6185,7^{* *}$ \\
\hline CV $(\%)$ & & 1,5 & 1,2 \\
\hline
\end{tabular}

\footnotetext{
${ }^{1}$ Médias seguidas de mesma letra, na vertical, não diferem estatísticamente entre si pelo teste de Tukey a 5\% de probabilidade.
} 
Aplicação seqüencial de herbicidas...

Tabela 4. Controle (\%) das plantas daninhas alvos, aos 7, 14 e 21 dias após o tratamento (DAT), pelos herbicidas aplicados em pós-emergência no feijoeiro. Fazenda Experimental Gralha Azul/PUC, Fazenda Rio Grande, PR. $1999 / 2000$.

\begin{tabular}{|c|c|c|c|c|}
\hline \multicolumn{2}{|c|}{ Tratamento } & \multicolumn{3}{|c|}{ Controle $(\%)$} \\
\hline Manejo & Pós-emergente & 7 DAT & 14 DAT & 21DAT \\
\hline Sulfosate $+2,4-\mathrm{D}$ & Fluazifop-butil/fomesafen & $94 \mathrm{a}$ & $98 \mathrm{a}$ & $99 \mathrm{a}$ \\
\hline Sulfosate $+2,4-D$ & Fluazifop-butil/fomesafen+bentazon & $94 \mathrm{a}$ & 98 a & 99 a \\
\hline Sulfosate $+2,4-\mathrm{D}$ & Testemunha & $0 \mathrm{c}$ & $0 \mathrm{c}$ & $0 \mathrm{c}$ \\
\hline Sulfosate// paraquat & Fluazifop-butil/fomesafen & 94 a & 98 a & 98 a \\
\hline Sulfosate// paraquat & Fluazifop-butil/fomesafen+bentazon & 94 a & $98 \mathrm{a}$ & $98 \mathrm{a}$ \\
\hline Sulfosate// paraquat & Testemunha & $0 \mathrm{c}$ & $0 \mathrm{c}$ & $0 \mathrm{ca}$ \\
\hline Sulfosate//(paraquat+diuron) & Fluazifop-butil/fomesafen & 94 a & $98 \mathrm{a}$ & 98 a \\
\hline Sulfosate//(paraquat+diuron) & Fluazifop-butil/fomesafen+bentazon & 94 a & $98 \mathrm{a}$ & $98 \mathrm{a}$ \\
\hline Sulfosate//(paraquat+diuron) & Testemunha & $0 \mathrm{c}$ & $0 \mathrm{c}$ & $0 \mathrm{c}$ \\
\hline Sulfosate//diquat & Fluazifop-butil/fomesafen & 94 a & 98 a & 98 a \\
\hline Sulfosate//diquat & Fluazifop-butil/fomesafen+bentazon & 94 a & 98 a & 98 a \\
\hline Sulfosate//diquat & Testemunha & $0 \mathrm{c}$ & $0 \mathrm{c}$ & $0 \mathrm{c}$ \\
\hline Sulfosate//(paraquat+diuron)+diquat & Fluazifop-butil/fomesafen & 94 a & 98 a & 98 a \\
\hline Sulfosate//(paraquat+diuron)+diquat & Fluazifop-butil/fomesafen+bentazon & 94 a & 98 a & 98 a \\
\hline Sulfosate//(paraquat+diuron)+diquat & Testemunha & $0 \mathrm{c}$ & $0 \mathrm{c}$ & $0 \mathrm{c}$ \\
\hline Testemunha & Fluazifop-butil/fomesafen & $11 \mathrm{~b}$ & $14 \mathrm{~b}$ & $14 \mathrm{~b}$ \\
\hline Testemunha & Fluazifop-butil/fomesafen+bentazon & $11 \mathrm{~b}$ & $14 \mathrm{~b}$ & $14 \mathrm{~b}$ \\
\hline Testemunha & Testemunha & $0 \mathrm{c}$ & $0 \mathrm{c}$ & $0 \mathrm{c}$ \\
\hline $\bar{F}$ & & $648,6^{* *}$ & $963,8^{* *}$ & $968,2^{* *}$ \\
\hline $\mathrm{CV}(\%)$ & & 2,0 & 1,6 & 1,6 \\
\hline
\end{tabular}

\footnotetext{
${ }^{1}$ médias seguidas de mesma letra, na vertical, não diferem estatísticamente entre si pelo teste de Tukey a 5\% de probabilidade

2 aplicação única de manejo - AUM - mistura em tanque

${ }^{3}$ aplicação seqüencial de manejo - ASM
}

Na Figura 1 (A, C e E) pode-se observar nas testemunhas, que o nível de infestação das plantas daninhas foi bastante elevado, com 578, 97 e 72 plantas $/ \mathrm{m}^{2}$, para leiteiro, nabiça e capim-colchão, respectivamente

Na Figura 2 (A e C) pode-se observar o número de plantas/m de leiteiro e capim-colchão, antes da aplicação do herbicida. Verifica-se, para ambas as espécies, uma densidade menor, com um nível de infestação $47 \%$ inferior na ASM em relação a AUM. Na Figura 2 (B e D) estão representadas as densidades em função do estádio de desenvolvimento do leiteiro e capim-colchão, antes da aplicação do herbicida. Observa-se que, além da densidade de plantas ser inferior na ASM, a maior parte das plantas, 76 e $60 \%$ do leiteiro e capim-colchão, respectivamente, estavam no estádio de até duas folhas ou um perfilho desenvolvido, ao passo que, na AUM, 55 e $58 \%$ do leiteiro e capim colchão, respectivamente, encontravam-se no estádio entre duas a quatro folhas ou perfilhos desenvolvidos. Esses resultados mostram que o manejo seqüencial reduziu não só a densidade, como também proporcionou uma uniformização do estádio de desenvolvimen- to das infestantes no momento da aplicação do herbicida, o que permite uma maior flexibilidade na redução da dose ou aplicação seqüencial do herbicida, onde a segunda aplicação só será feita se houver necessidade. Resultados semelhantes foram encontrados em outros trabalhos (Souza Neto \& Oliveira, 1999; Vidal et al., 1999; Fleck et al., 2000, Portela \& Cobucci, 2000; Purissimo; 2000).

Pode-se observar, na Figura 2 E, a densidade de nabiça antes da aplicação do herbicida. Verifica-se que, o número de plantas $/ \mathrm{m}^{2}$ na ASM foi maior, com um nível de infestação $50 \%$ superior em relação a AUM. Na Figura 2 F, estão representadas as densidades de nabiça em função do estádio de desenvolvimento, antes da aplicação do herbicida. Verificase que, embora o número de plantas $/ \mathrm{m}^{2}$ na ASM tenha sido superior em relação a AUM, 99\% das plantas de nabiça presentes estavam no estádio de desenvolvimento de até duas folhas, comprovando que a ASM promove uma uniformização do estádio de desenvolvimento das infestantes, o que facilita e proporciona uma boa eficácia dos herbicidas aplicados em pós-emergência (Tabela 4). 
A - leiteiro

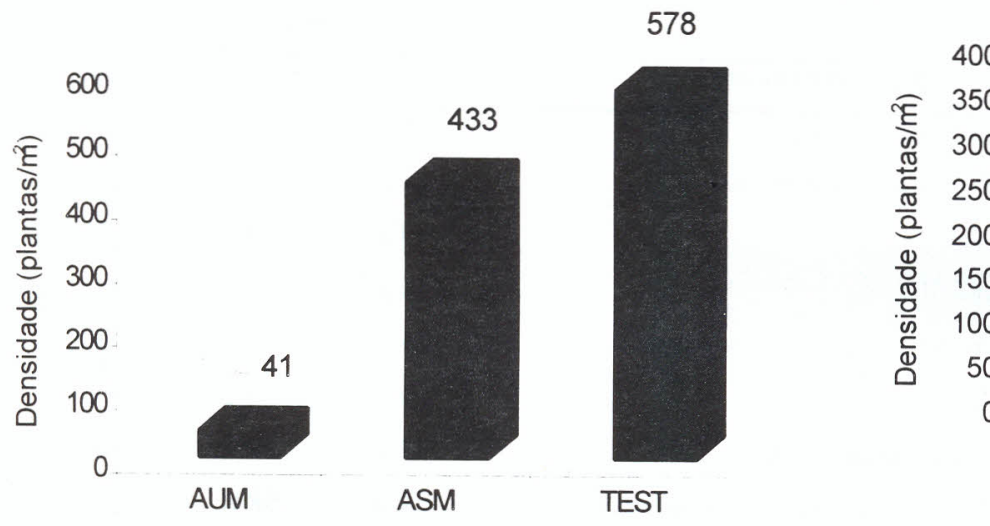

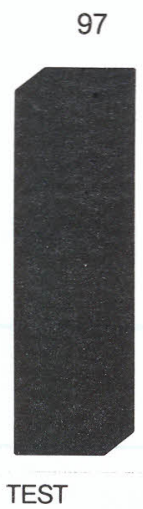

C - nabiça

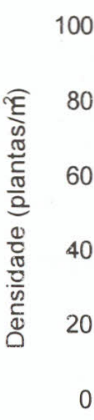

00

80
60
40
20
0

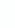

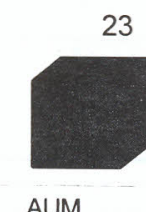

AUM

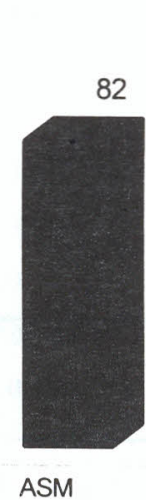

E- capim-odchã

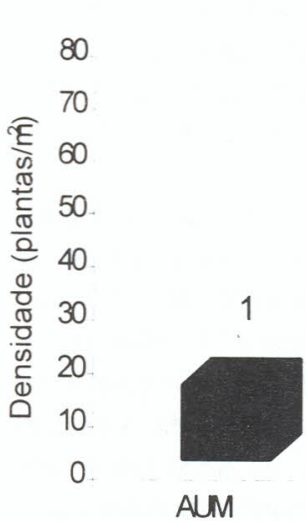

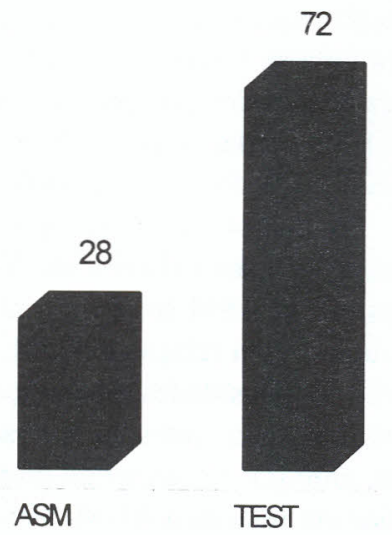

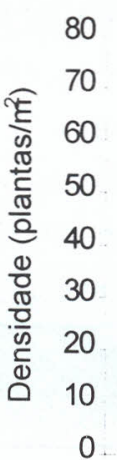

23

AUM

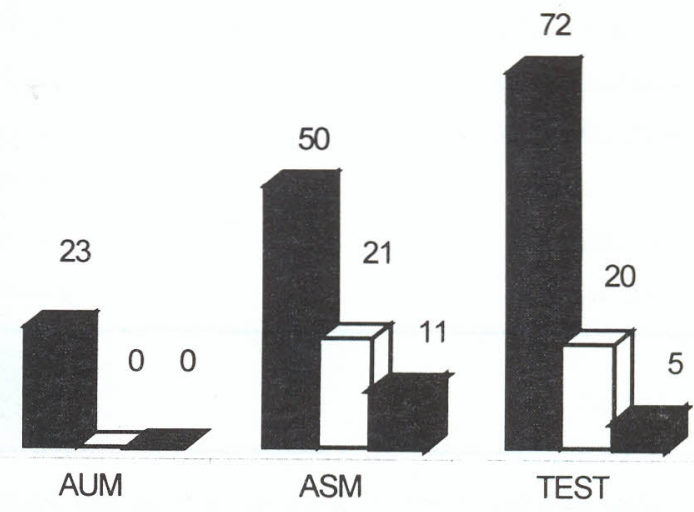

B - leiteiro

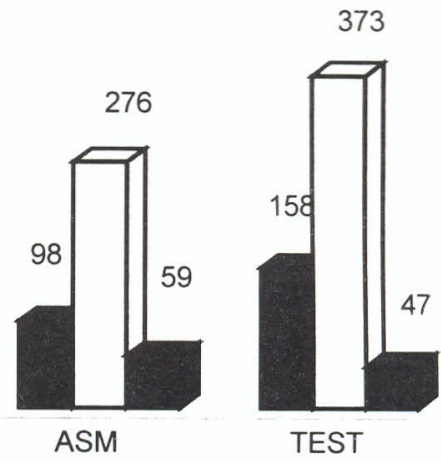

até 2 folhas $\square^{2-4}$ folhas amais 6 folhas

\section{D - nabiça}

até 2 folhas $\square^{2-4}$ folhas mais 6 folhas

$$
\text { F - capim-colchão }
$$
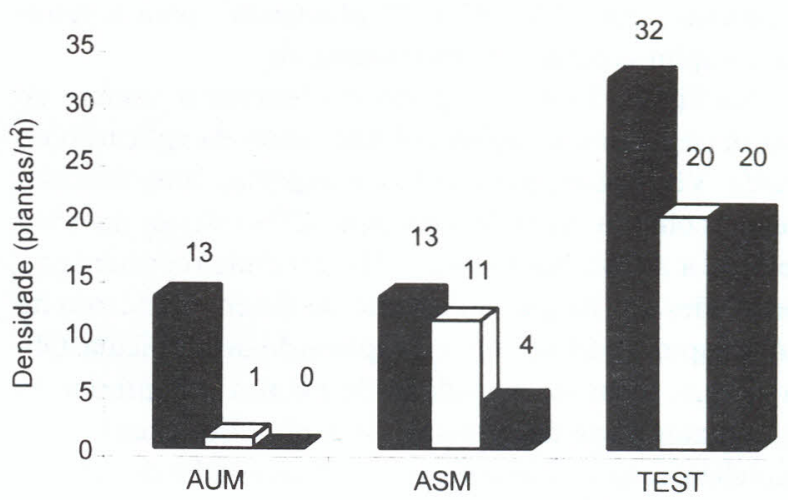

até 1 perfilho $\square^{2-4}$ perfilhos mais 4 perfilhos

Figura 1. Densidade total (gráficos A, C e E) e densidade em função do estádio de desenvolvimento (gráficos B, D e F) de leiteiro, nabiça e capim colchão, na semeadura do feijoeiro, antes da aplicação seqüencial de manejo. Fazenda Experimental Gralha Azul/PUC, Fazenda Rio Grande, PR. 1999/2000. 


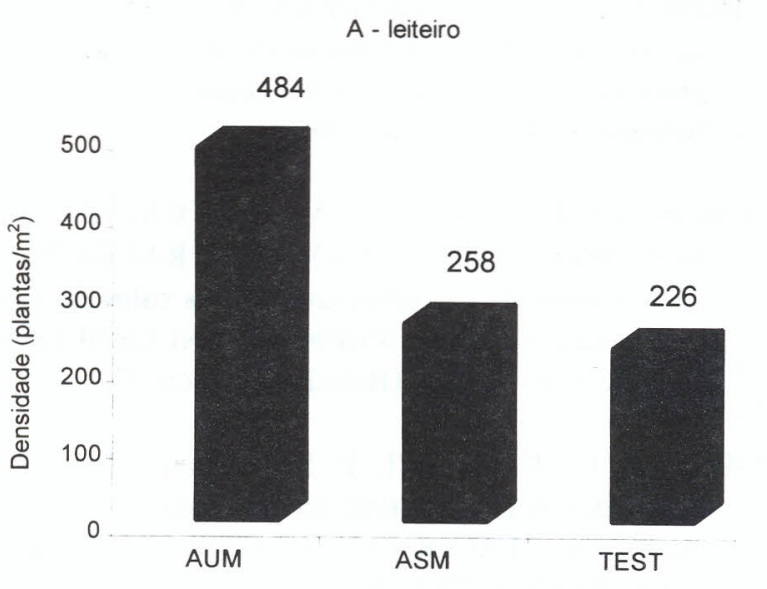

C -capim-colchão
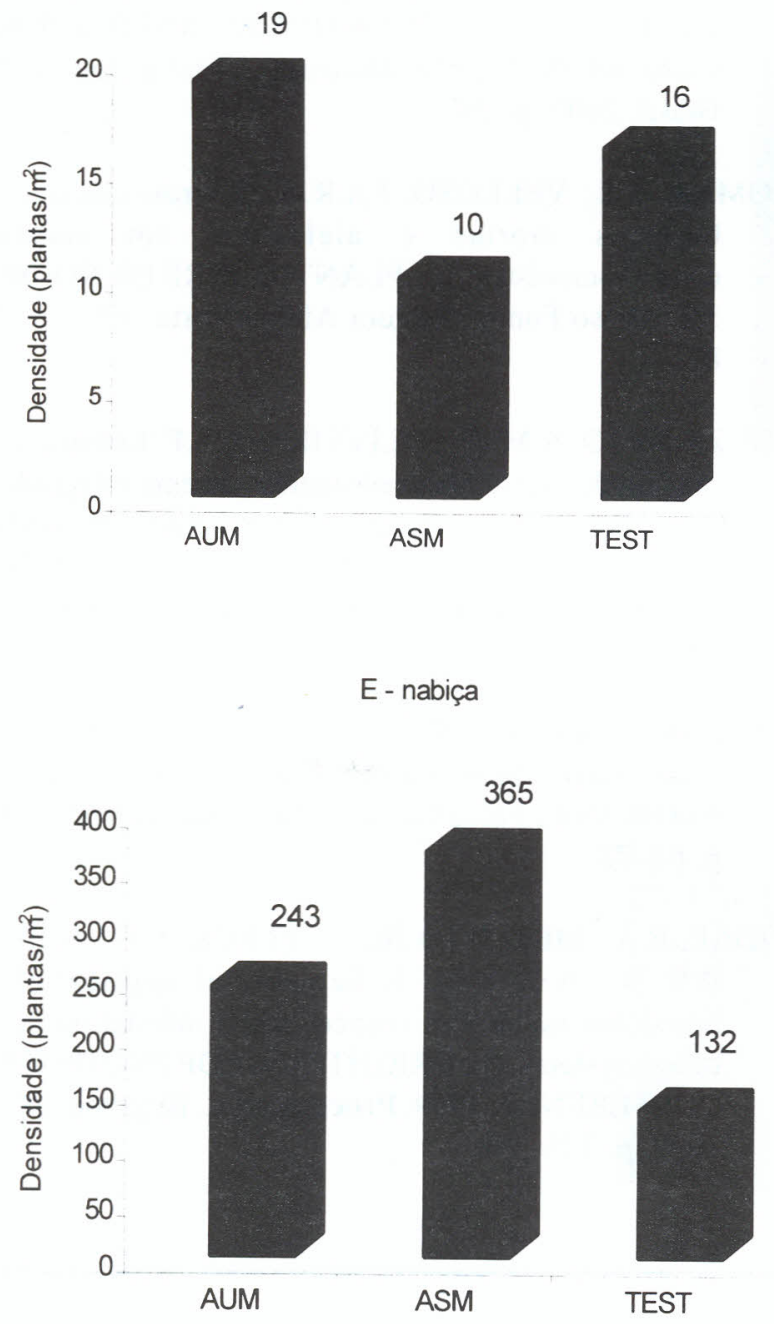

B - leiteiro

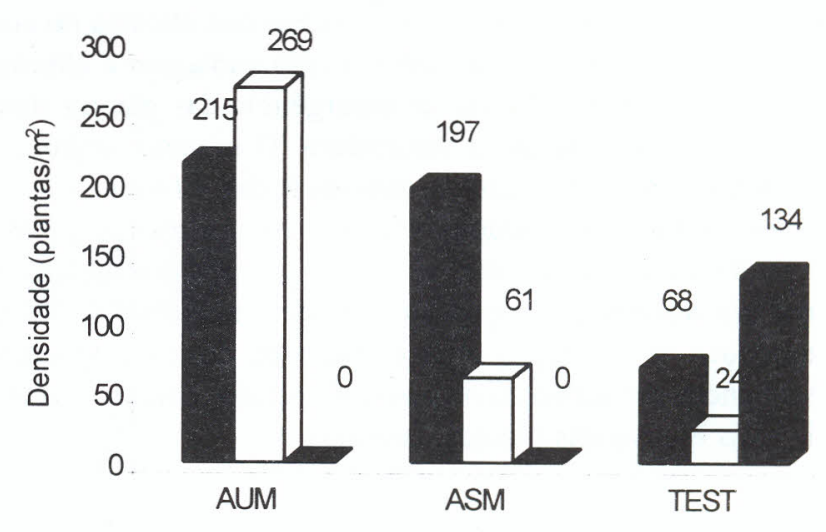

até 2 folhas $\square^{2-4}$ folhas mais 4 folhas

D - capim-colchão

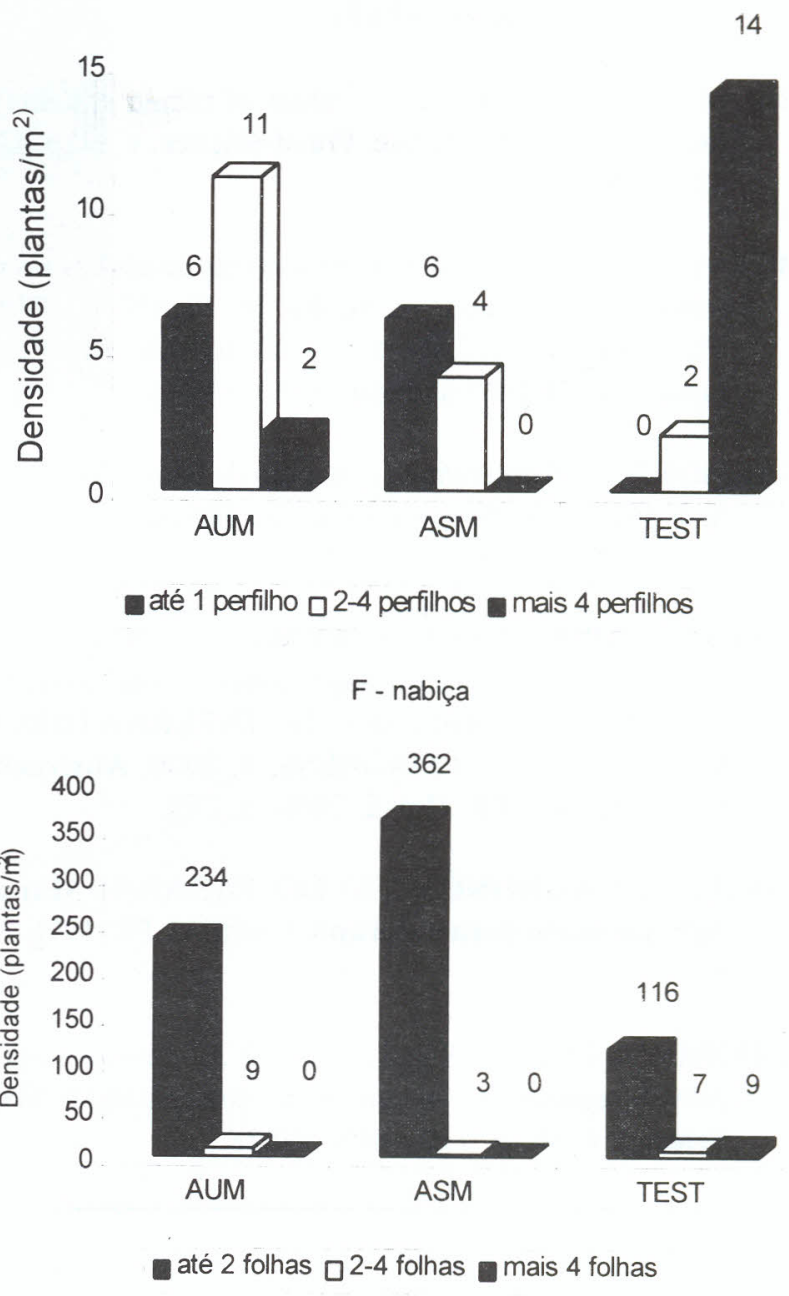

Figura 2. Densidade total (gráficos A, C e E) e densidade em função do estádio de desenvolvimento (gráficos B, D e F) do leiteiro, capim colchão e nabiça, antes da aplicação do pós-emergente no feijoeiro. Fazenda Experimental Gralha Azul / PUC, Fazenda Rio Grande, PR. 1999/2000. 


\section{CONCLUSÕES}

O manejo seqüencial apresentou boa eficácia no controle da cobertura vegetal, tendo como vantagem a eliminação dos diferentes fluxos de emergência das plantas daninhas que antecederam a semeadura. $\mathrm{O}$ manejo seqüencial possibilita ainda redução da densidade das infestantes assim como uniformiza o estádio de desenvolvimento das mesmas quando da aplicação dos herbicidas de pós-emergência. $\mathrm{O}$ manejo seqüencial proporciona também maior flexibilidade na época de aplicação e na redução da dose ou aplicação seqüencial do herbicida de pós-emergência, com um controle mais efetivo das plantas daninhas.

\section{LITERATURA CITADA}

ALMEIDA, F.S. de. Controle de plantas daninhas em plantio direto. Londrina: Instituto Agronômico do Paraná, 1991. 34 p. (Circular $n^{\circ} 67$ ).

BAUMAN, T.T.; ROSS, M.A. Effect of tillage systems on the persistence of atrazine. Weed Science, v. 31, p. 423426. 1983.

BUZATTI, W.J. de S. Controle de plantas daninhas no sistema plantio direto na palha. In: PLANTIO DIRETO: ATUALIZAÇÃO TECNOLÓGICA. São Paulo: Fundação Cargill/Fundação ABC, 1999.p. 97-111.

CARMONA, R. Problemática e manejo de bancos de semente de invasoras em solos agrícolas. Planta Daninha, v. 10, n. 1/2, p. 5-16, 1992.

FLECK, N.; MEROTTO Jr., A; VIDAL, R. A. Reduction of weed infestation in no-tillage systems with sequential application of herbicides. In: INTERNATIONAL WEED SCIENCE CONGRESS, 3, 2000, Abstracts... Foz do Iguaçu, PR, Brasil, 2000. p. 252.

INSTITUTO AGRONÔMICO DO PARANÁ. Manual Agropecuário para o Paraná. Londrina, PR, 1976. 387 p.

O'DOnOVAn,J.T.; O'Sullivan, P.A. Amine salts of growth regulator herbicides antagonize paraquat. Weed Science, v. 30, p. $605-608$. 1982a.
O'DONOVAN, J.T.; O'SULLIVAN, P.A. The antagonistic action of 2,4-D and bromoxynil on glyphosate phytotoxicity to barley (Hordeum vulgare). Weed Science, v. 30, p. 30-34, 1982 b.

OLMOS, I.L.J.; CARDOSO,A.; CARVALHO, A. P.; HOCHMÜLER, D. P.; FASOLO, P.J.; RAUEN, M.J. Levantamento de reconhecimento dos solos do Estado do Paraná. Londrina: EMBRAPA/SNLCS/SUDESUL/ IAPAR, 1984. 412 p. (Boletim Técnico, 57).

PORTELA, C; COBUCCI, T. Sequential application of herbicides at pre-planting for the control of weeds in bean crops. INTERNATIONAL WEED SCIENCE CONGRESS, 3, 2000, Abstracts... Foz do Iguaçu, PR, Brasil, 2000. p. 17.

PURISSIMO, C. Effectiveness of postemergence herbicides following early preplant applications of sulfosate in notillage soybean. INTERNATIONAL WEED SCIENCE CONGRESS, 3, 2000, Abstracts... Foz do Iguaçu, PR, Brasil, 2000. p. 253.

ROMAN, E.S.; VELLOSO, J.A.R.O. Controle cultural, coberturas mortas e alelopatia em sistemas conservacionistas. In: PLANTIO DIRETO NO BRASIL. Passo Fundo: Editora Aldeia Norte, 1993. p. 7784.

SOUZA NETO, A.M. de.; OLIVEIRA, A.L.F. Estratégias de manejo de populações resistentes: sistema integrado de controle de plantas daninhas. In: CURSO DE MANEJO DA RESISTÊNCIA DE PLANTAS DANINHAS AOS HERBICIDAS, 2, Ponta Grossa, PR, 1999. p. 4148.

VELLOSO, J.A.R.O; SOUZA, R.O. Plantas daninhas no sistema plantio direto na palha. In: PLANTIO DIRETO NO BRASIL. Passo Fundo: Editora Aldeia Norte, 1993. p. 61-73.

VIDAL, R.A.; MEROTTO JR, A.; FLECK, N.G.; OLIVEIRA, N.; ASSUITI, J. Sequencial application of burndown herbicides reduces weed infestation in notillage systems. In: BRIGHTON CROP PROTECTION CONFERENCE, 1999. Proceedings... Brighton: BCPC, 1999. p. $325-330$. 